\title{
Sacral nerve stimulation for the treatment of faecal incontinence secondary to a pelvic war injury: a case report
}

\author{
Jonathan J R Richardson, ${ }^{1}$ D Bowley, ${ }^{1,2}$ S Karandikar ${ }^{1}$
}

\begin{abstract}
- Additional material is published online only. To view please visit the journal online (http://dx.doi.org/10.1136/ jramc-2013-000057)

${ }^{1}$ Department of General Surgery, Heart of England NHS Foundation Trust, Birmingham, UK

${ }^{2}$ Royal Centre for Defence Medicine, Birmingham, UK
\end{abstract}

\section{Correspondence to} JJR Richardson, Department of General Surgery, Heart of England NHS Foundation Trust, Birmingham Heartlands Hospital, Bordesley Green East Birmingham B9 5SS, UK; dr.richardson@btinternet.com

Received 4 March 2013 Revised 23 April 2013 Accepted 27 April 2013 Published Online First 30 May 2013

To cite: Richardson JJR, Bowley D, Karandikar S. J $R$ Army Med Corps 2014;160: 58-60.

\section{ABSTRACT}

Faecal incontinence can be physically and socially disabling and the level of unmet need in men appears to be high. We report a case of faecal incontinence in a 29-year-old, heterosexual serviceman who sustained a trans-pelvic gunshot injury (without perineal injury) while on active duty. Despite apparently successful surgical treatment, the patient presented to our colorectal department 7 years after injury with disabling faecal incontinence. Following assessment, sacral nerve stimulation (SNS) was initiated with excellent results. We report the successful use of SNS to treat faecal incontinence resulting from a combat gunshot injury. We recommend that surgeons carefully document the anatomical position of retained ballistic fragments after gunshot or blast fragment injury and that attention should be paid to the functional results in a patient's follow-up after intestinal surgery.

\section{INTRODUCTION}

It is estimated that approximately $0.7 \%$ of adults more than 40 years of age living at home in the UK experience major faecal incontinence (FI). Despite the fact that FI is often thought of as a problem predominately for women, prevalence of major FI appears to be equal between the sexes and the level of unmet need in men appears to be high. ${ }^{1}$

FI can be physically and socially disabling. Aetiological factors include traumatic (eg, obstetric), neurological, congenital and iatrogenic. ${ }^{2}$ A proportion of patients will not respond to conservative measures (including dietary, medical and behavioural modifications) and should be considered for surgery. Several corrective operations are available; some show initial success that deteriorates over time and the complication rate approaches $100 \%$ in some series. ${ }^{2}$ Sacral nerve stimulation (SNS) is a minimally invasive approach to the management of FI. SNS is safe and effective and has been shown to restore or improve continence and quality of life. ${ }^{3}$

Wexner and colleagues from The Cleveland Clinic, Florida, conducted a prospective multicentre study looking at the safety and efficacy of SNS in patients with FI in 120 patients (91.7\% female) recruited from all SNS candidates. At 12 months they reported that $40 \%$ of patients had perfect continence, a further $30 \%$ had more than $75 \%$ improvement in symptoms and incontinent episodes decreased from a mean of 9.4 to 1.9 per week. The authors reported no unanticipated adverse device effects. ${ }^{4}$

Initially SNS was indicated for use only in FI of neurological origin in patients with a weak but structurally intact sphincter. It has been proposed that SNS could be a therapeutic option for FI in patients with an anal sphincter lesion particularly as the long-term results of sphincteroplasty have been disappointing. ${ }^{5}$ In 2012, Ratto et al from Rome conducted a review of SNS in 119 patients with FI and a documented external and/or internal anal sphincter lesion. The average number of FI episodes decreased from a mean of 12.1 to 2.3 per week and the ability to defer defaecation increased significantly.

\section{CASE REPORT}

A 29-year-old, heterosexual serviceman sustained a trans-pelvic gunshot injury while on active service. He underwent an emergency laparotomy and primary repair of a proximal colonic perforation without bowel resection or stoma formation. Small fragments of the projectile were evident throughout the pelvis at the time of surgery. He had a prolonged hospital recovery, but once he had recovered from his injury, it became apparent to the patient that he had developed faecal urgency and urge FI. Prior to the injury, there had been no history of bowel dysfunction or anorectal symptoms. The soldier had no history of previous anal surgery or trauma and he used to open his bowels once a day.

The symptoms of faecal urgency and urge FI occurred with both formed and liquid stool. His bowels opened up to five times per day and he was incontinent to formed and liquid stool more than once per day. He experienced no passive faecal soiling. He had poor flatus control and he could not differentiate flatus from stool. He experienced incontinence to flatus more than once per day. $\mathrm{He}$ did not resort to wearing a pad but chose a job with easy access to the toilet to minimise social embarrassment. He lived in daily trepidation of FI with a consequent major impact on his quality of life. His symptoms were resistant to conservative measures.

He was referred to our colorectal clinic 7 years after his injury when he was assessed using the Cleveland Clinic Faecal Incontinence Score, a continence tool which attempts to assess the severity of FI combining the nature of the incontinence and the requirement for lifestyle alteration including the need to wear a pad with a range of 0-20 composed of five domains each scoring $0-4$, where a total of 0 equates to perfect continence and 20 means complete incontinence. The serviceman scored 16/20 comprised of the following components: FI more than once per day to solid (4/4), 
liquid (4/4) and gas (4/4), the need for an incontinence pad (0/ 4 ) and lifestyle alteration (4/4).

On examination, he had a healed, traumatic wound in the right lumbar region and a midline laparotomy scar (Figure 1). His perineum appeared normal with no evidence of scarring or trauma. Digital rectal examination revealed an anatomically normal anal canal with apparently normal resting tone; however, squeeze pressure was markedly reduced.

Plain x-ray documented multiple retained, small, metallic fragments of the projectile throughout the pelvis. Sigmoidoscopy and mucosal biopsies were unremarkable and an MRI scan of the lumbosacral spine was normal. Anorectal physiology studies revealed a resting pressure of $55 \mathrm{~mm} \mathrm{Hg}$ (normal $>60 \mathrm{~mm} \mathrm{Hg}$ ) and voluntary contraction pressure that was markedly reduced at $35 \mathrm{~mm} \mathrm{Hg}$ (normal $>60 \mathrm{~mm} \mathrm{Hg}$ ), with an inability to maintain a voluntary contraction. The recto-anal inhibitory reflex was normal. Rectal distension sensory thresholds were reduced. Endoanal ultrasound revealed intact internal and external sphincters with evidence of external sphincter scarring.

After a multi-disciplinary conference it was agreed with the patient that a temporary SNS electrode would be trialled. This trail was successful and a permanent, implanted pulse generator was subsequently inserted (Figure 2).

Postoperatively he experienced a reduction in episodes of faecal urgency and urge FI and an improved ability to successfully defer defaecation. A 2-week continence diary revealed 'controlled bowel emptying' on $89 \%(16 / 18)$ of occasions compared with 62\% (24/39) previously and 'rushed bowel emptying' on only two occasions compared with 15 prior to SNS implantation.
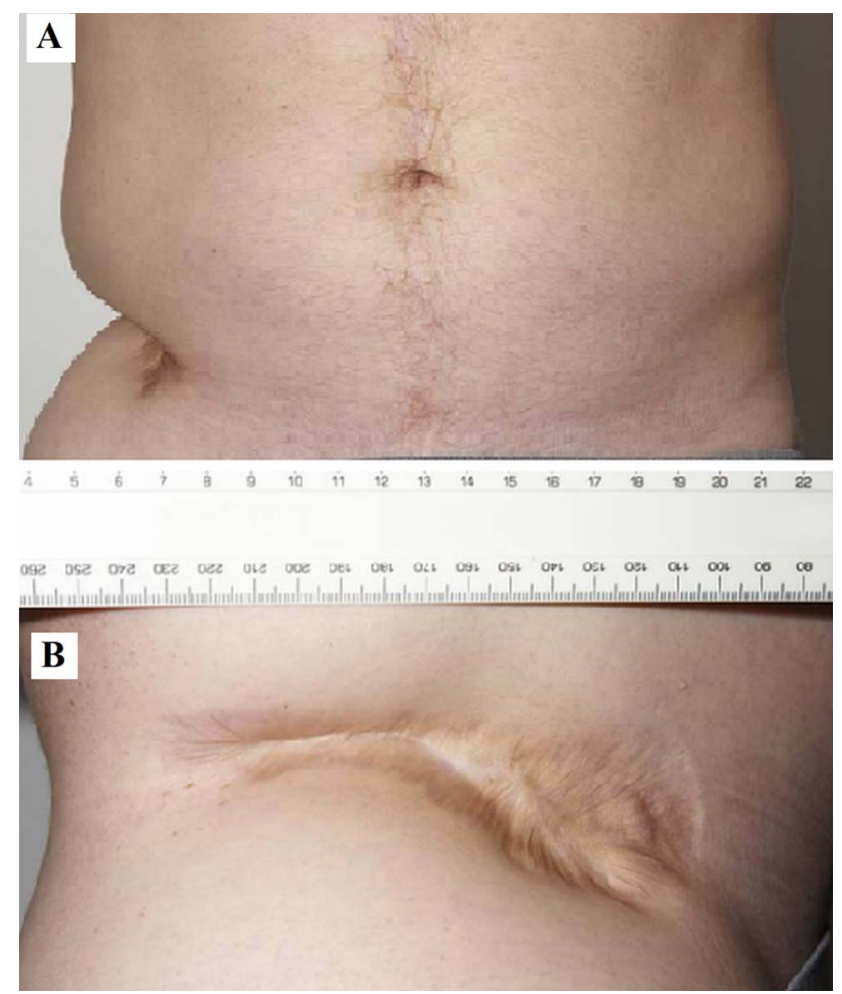

Figure 1 A traumatic wound in the right lumbar region from a combat gunshot injury viewed from anterior posterior (A) and right lateral (B).

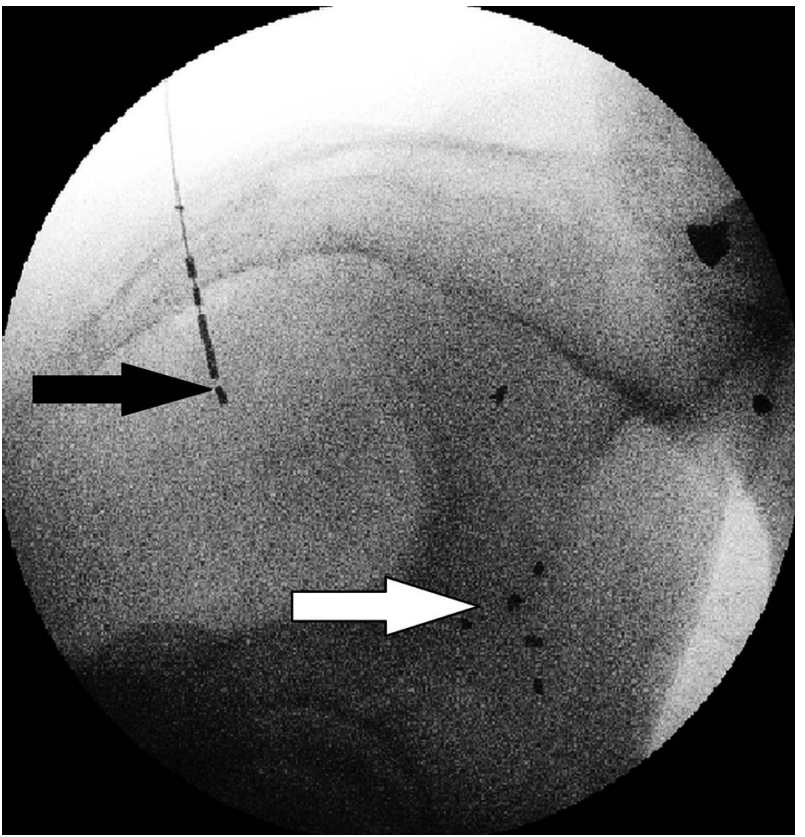

Figure 2 An intraoperative radiograph of a percutaneously introduced permanent implanted pulse generator (black arrow) and residual fragments of the projectile within the pelvis (white arrow).

Following SNS, the soldier achieved a score of 2 on the Cleveland Clinic Faecal Incontinence Score. He has experienced such a significant improvement in his continence and quality of life that he has been able to return to full-time military employment (P3; medically fit with minor employment limitations). $\mathrm{He}$ remains well with improved continence 17 months after the permanent SNS implantation.

\section{DISCUSSION}

FI in men has received less attention than in women; however, the detrimental impact of FI in men can be high and men may be less likely to seek help. ${ }^{1}$ This soldier presented to the colorectal clinic 7 years following his pelvic war injury highlighting the stigma associated with FI. His symptoms, structural and physiological features were in keeping with an external sphincter injury, both anatomical and functional (eg, nerve injury to sphincter), with secondary sensitivity to rectal distension. In this instance, the fragmentation of the projectile that occurred when it struck the pelvic bones and subsequent passage of these projectiles throughout the pelvis must have damaged the anal sphincter and its innervation.

A combat gunshot injury without perineal injury has not previously been documented as a cause for FI. SNS was successfully implemented in this unusual clinical situation where there was a damaged, but intact, anal sphincter complex and associated neurological injury. Other techniques, such as an overlapping sphincter repair and artificial bowel sphincter implant, were not considered appropriate in this case first because the sphincteric ring was intact and second due to the significant surgical morbidity and high failure rates associated with artificial sphincter surgery.

As well as considering SNS for incontinence such as this, we further recommend that surgeons carefully document the anatomical position of retained ballistic fragments after gunshot or blast fragment injury and that attention should be paid to the functional results in a patient's follow-up after intestinal surgery. 


\section{CONCLUSIONS}

FI in men is often unreported and may occasionally be the result of combat trauma. A trans-pelvic trajectory of ballistic injury may damage the pelvic nerves to such an extent that FI may result. All options should be considered for FI treatment including SNS; the position of retained ballistic fragments should be documented

Contributors JR: study conception and design, acquisition of data, analysis and interpretation of data, drafting the article, revising the article, final approval. DB: revising the article, final approval. SK: study conception and design, revising the article, final approval.

Competing interests None.

Patient consent Obtained.
Provenance and peer review Not commissioned; externally peer reviewed.

\section{REFERENCES}

1 Perry S, Shaw C, McGrother C, et al. Prevalence of faecal incontinence in adults aged over 40 years or more living in the community. Gut 2002;50:480-4.

2 Hayden DM, Weiss EG. Faecal incontinence: aetiology, evaluation, and treatment. Clin Colon Rectal Surg 2011;24:64-70.

3 Mellgren A, Wexner SD, Coller JA, et al. Long-term efficacy and safety of sacral nerve stimulation for fecal incontinence. Dis Colon Rectum 2011;54:1065-75.

4 Wexner SD, Coller JA, Devroede G, et al. Sacral nerve stimulation for fecal incontinence: results of a 120-patient prospective multicenter study. Ann Surg 2010;251:441-9.

5 Ratto C, Litta F, Parello A, et al. Sacral nerve stimulation in faecal incontinence associated with an anal sphincter lesion: a systematic review. Colorectal Dis 2012;14: e297-304. 